and completely dissolved, whatever be the amount of peptone it yields.

J. But when it is more important rapidly to restore mus. cular force than to allay gastro-intestinal pain, we should, on the contrary, give such food which, the digestive force being the same. yields the greatest weight of peptone, though that food be likely to dissolve and digest slowly. (See Proposition 17.)

K. He who digests with one organ only, (stomach or pan creas, ) is thereby put on half allowance as regards peptone; and he who eats only albumen or gelatinous tissue, (instead of caseine or musculine, which yield double as much peptone,) is also put upon half allowance; and with a normal and equal digestive force, is only half nourished. (See Proposition 17.)

In the two preceding cases, an over-activity either of the one organ (first case), or of both organs (second case), may occur, and extract from the food the full allowance of peptone. But we must not long trust this extreme functional exertion, for any persisting over-activity must sooner or later end in ex haustion.

L. We should not give for a long time one kind only of nitrogenous food, not only because one kind of azotized aliment is not capable of repairing the waste of the organism, but also because the same article of food given exclusively and con tinuously (for a week for instance) no longer excites gastric secretion, and no longer fully undergoes the digestive transformation.

M. Most of the peptones upon which I have made experiments, have the peculiarity of not being precipitated by neutral acetate of lead. Now, in all cases where the albuminoid matters of the urine happen to be of the albuminose kind, they remain in solution, in spite of the acetate of lead used to precipitate them. They therefore mask the sugar more effectually than all other ingredients of the urine when the potash and copper test is employed. The presence of sugar may thins be overlooked when it really exists in the urine.

\section{ON THE}

USE OF THE DRAINAGE-TUBES OF $M$ CHASSATGNAC IN THE TREATMENT OF ABSCESSES, \&C.

By P. C. PRICE, EsQ., M.R.C.S., SURGEON TO THE GREAT NORTHERN HOSPITAL; TO THE MIETROPOLITAN INSTITUTION FOR SCROFULOUS CHLDDREN AT MARGATI, BTC.

From a notice which lately appeared in the columns of THE LANCET, it would seem that the introduction of the drainagetubes of M. Chassaignac, in the treatment of certain collections of flnid, is quite a novel and recent introduction into the practice of English surgery. As far back as the autumn of 1856 , I was familiar with this method, as illustrated in the practice of the inventor, and investigated the subject in the wards of the Laraboissière Hospital, in company with $\mathrm{Mr}$. Spencer Wells, Dr. M'Leod, of Glasgow, and my brother, Mr. W. P. Price. M. Chassaignac then explained his mode of treatment, and presented us with specimens of tubing, such as he was in the habit of using.

On my return to England, I gave an early trial to these appliances, at an institution specially devoted to the treatment of scrofulous affections in children. Personal experience led me to form a less favourable opinion of their value than I had heard expressed by the inventor; and in a paper which I had the honour of reading before the Medical Society of King's College, more than a year ago- "Observations upon certain Strumous Swellings"- I briefly stated the results of my own acquaintance with the system.

From various features exhibited in the treatment of my own eases, I was induced to limit the application of the tubing. The earliest inconvenience I experienced was the constant closure of the tube by the slightest pressure upon its circum. ference, owing to the highly elastic and flexible nature of the vulcanized indiarubber. Upon substituting tubes of guttapereha, this slight difficulty vanished. Considerable local disturbance was not unlikely to follow the retention of a portion of tubing, especially in sensitive and debilitated patients.

The cases I fond most eligible for this method of treatment were collections of purulent matter in the cellular structure which were not of long existence; and although benefit cer. tainly accrued in some instances, still I could not divest myself of the idea that the tube acted more in the capacity of a seton than of a waste-pipe. In abscesses truly scrofulous, and of long standing, though unconnected with dead or carious bone, he system of draining is frequently of little value. The arrest fecretion from such a suppurating surface is oftentimes diffialt, while the peculiar character of the pus, so often curdy thick, and focculent, is in no way fitted for a spontaneous and ready exit through the outlets in a necessarily limited-sized tabing. To cause the obliteration of the secreting surfaces of a abscess of this nature, after the usual means have been expended in vain, it will become necessary to change or entirely estroy the suppurating surface. Injections of stimulating fuids may occasionally be beneficial, but to procure permanent obliteration by granulation and adhesion, it may be necessary to resort to a more heroic, yet more certain plan. When such an abscess is situated at a part of the body removed from important and vital structures, freely laying open the sac, and removing, in part or entirely, the thick, pulpy, and gelatinaform lining, by partial cutting, scraping, and tearing, will be attended with success. I have frequently resorted to this plan in extensive, long-standing abscesses in the cellular tissue, in the neighbourhood of the thigh and buttock. The cleaned surfaces rapidly take on a new action, and the cavity sensibly diminishes or entirely closes in a limited space of time. Oftentimes, however, the situation of such an abscess forbids the surgeon dealing with it in this way, and he is well content to resort to milder means. The rapid and constant secretion of a large chronic strumous collection of purulent fluid is sometimes judiciously treated by withdrawing, at stated intervals, the pent-up matter, by means of a canula furnished with a stop-cock. I have treated such abscesses with satisfaction. Care should be taken to avoid the admixture of air with the fluid. Should the secretion after a time show no signs of diminishing, then manipulation of the tumour, irritating its interior with stimulating injections, as iodine, the salts of the mineral acids, or even the diluted acids, may be adopted. The introduction of the drainage-tube, on the failure of the above means, may, perchance, enable the cavity to close; but then the chief virture of the tubing will, I imagine, arise from its acting in the light of a seton, and not as a drain.pipe.

The use of the drainage apparatus of $\mathrm{M}$. Chassaignac, however, is attended with considerable advantages in the treatment of large suppurating tracts dependent upon the existence of deep-seated mischief-as dead or carious states of neighbouring bone. The aim of the surgeon in such a complicated condition of lesion is to maintain the existence of a free and ready discharge of the secretion till such time as separation of the morbid structures takes place. It is important that cleanliness should be strictly observed, both for the comfort of the patient and the sanitary condition of the ward he occupies. In cases of lumbar abscess, the judicious application of the tubing is most beneficial, while many unpleasant symptoms, arising frequently from the contact of the secreted purulent fluid with the adjacent skin, are avoided.

In certain abscesses of large size, the introduction of two, three, or more tubes, is undoubtedly attended with benefit, and after a time the patient is enabled to manage the apparatus himself, thereby saving the troable and expense of oftrepeated dressings and necessary attendance.

The detail of cases is not required to prove the occasional value of the drainage system, but my own experience will not allow me to admit that it is efficacious as a means of cure in a large class of cases to which it is oftentimes applied. Green-street, Grosvenor-square, Fcb. 1859.

\section{REPORT OF A CASE OF}

\section{POISONING BY CHLORIDE OF BARIUM.} By JOHN WALSH, Esq., M.R.C.S. \& L.S.A., Manchester.

Sarah A - , aged twenty-two years, a healthy young woman, a barmaid, took, according to her own statement, less than a teaspoonful of the chloride of barium, mistaking it for Epsom salts, at half-past twelve P.M. on the 1st of October, 1858. Her master was in the habit of using the salt as a test for vinegar, and he kept it carelessly on a shelf in the bar, not being aware of its virulence as a poison. He cautioned the girl, however, on no account to meddle with it, an order which 
she admitted to have received, but said she had forgotten. In about half an hour, she became, as she expressed herself, deadly sick all over, felt sharp, burning pains in the stomach and bowels, and was obliged to go to the water-closet, where she remained a considerable time, having both vomited and been purged severely, the purging being accompanied with much straining. Her mistress now being made aware of the circumstances of the case, at once administered an emetic, and assisted its action by giving copious draughts of thin gruel. It unfortunately happened that a medical man could not be procured at the time, but a neighbouring druggist was consulted, who stated that there was no occasion for alarm, as the dose taken was much too small to cause death, but recommended, however, that a medical man should see the case."

At five minutes past two o'clock, I saw the girl, an hour and a half after she had taken the poison. She was then in the following condition:--She was lying on her back in bed; the face pale and anxious; eyes deeply sunken; surface of body cold; heart's action very feeble and irregular; pulse scarcely perceptible; tongue natural and warm; muscular power of the extremities almost gone, but sensation not affected; pupils natural; intelligence not impaired. Anything she drank was immediately rejected, mixed with ropy mucus. She complained of pain in the stomach and hypogastrium, lightness in the head, singing in the ears, twitching of the face, and "twisting" of the legs and arms. There was no muscular movement whatever noticeable.

I administered a strong solution of sulpnate of magnesia, had heat applied to the extremities, and sinapisms to the abdomen, and gave warm coffee and brandy in gruel from time to time. I may say I was in constant attendance upon her all the afternoon, and at nine P.M. her state was as follows:-The pains, vomiting, and purging had entirely left her; colour had returned to the lips; warmth gradually returning to the surface; pulse 60, regular, and pretty strong; no alteration in the condition of the muscular power, and she still complained of the twitching and twisting sensations, and of the noise in the ears. I had now fair bopes of recovery, and gave particular instructions with regard to the management of the case during the night, with orders to be sent for should any unfavourable change take place. I have reason to believe that my directions were but indifferently carried out, for I was subsequently informed that one of the two persons left in special charge of her became intoxicated during the night, and had to be sent away, and the other was, from physical causes, quite incapable of attending to her properly. I am aware that her master and mistress were very assiduous in their attentions to her, but having a large establishment to look after, I presume they could not be constantly with her. Be this as it may, I was sent for again at two o'clock in the morning, and found her much altered for the worse. The purging had returned, and all voluntary muscular power might be said to be entirely annihilated, except that she conld speak feebly, and malke some efforts to swallow. The most marked change, however, was $a$ slow and laboured state of the respiration, with copious effusion into the bronchial tubes, as evidenced by loud, loose râles heard all over the chest. She was still perfectly sensible. Sinapisms were applied to the chest and calves of the legs, and bottles of hot water to the extremities, and brandy and ammonia were given as freely as she could be got to take them. In a short time she fell asleep (for the first time), and slept for an hour, the breathing becoming slower and more laboured all the while, and the countenance assuming a dusky hue. Soon after three o'clock she awoke, muttered a word or two, and immediately became convulsed, and continued to work in the most fearful paroxysms for upwards of two hours, when she died, seventeen hours after she had taken the poison. During the fits, she had several abundant watery evacuations, and from the time she fell asleep she exhibited no sign of consciousness. No post-mortem examination was permitted, the coroner not considering it necessary.

Remarks. - Poisoning by the salts of barytes is a circumstance of rare occurrence, and but few opportunities have hitherto arisen for observing the full physiological action of these powerful agents upon the human system. In the fatal cases, too, whicin have been recorded, the quantities taken have been so large that death has rapidly ensued, and hence there has been little or no time for an accurate analysis of the symptoms in their order of sequence. The report now supplied is, I believe, unique in this respect : that while the subject of it took a dose

* The person alluded to, who is a very respectable man, asserts that he was misinformed with regard to the quantity taken. His impression was, that she had taken a portion corresponding to, and by mistake for, a pinch of salt, not salts. sufficiently large to cause death, she yet survived the poison for seventeen hours, affording thus a favourable occasion for carefully studying all the phenomena presented by the case. These may be briefly referred to as follows:-

1st. The primary action of the drug upon the gastro-intestinal mucous membrane as an irritant poison. This was mani. fested in from twenty-five to thirty minutes, and was extremely violent while it lasted. It gradually disappeared, and for several hours there was not the slightest symptom of it present.

2nd. Its effects upon the circulatory system, inducing feeble and irregular action of the heart, and almost complete annihi. lation of the arterial pulse.

3rd. Motor paralysis of the voluntary muscles, sensation re. maining intact. It should be here observed, that the paralysis was confined to the muscles supplied by the spinal nerves, at least until an advanced stage of the case; and that at first it was by no means absolute, the patient retaining for a considerable time the power of flexing the fingers; by degrees, however, even this became quite extinct.

4th. The sensations of twitching of the facial muscles and twisting of the limbs perceived by the patient. These were purely subjective, for there were no corresponding movements observable. The singing in the ears may, perhaps, be classed under this head also, although most likely depending upon a disturbed condition of the cerebral circulation.

$5 \mathrm{th}$. The lesion of respiration, which came on after the lapse of twelve hours, and which was associated with considerable impairment of the function of deglutition.

6th. The comatose state, which supervened in fourteen hours, up to which time the intelligence remained perfect.

7th. The convulsions, which succeeded the latter, and, having continued without intermission for nearly three hours, terminated in death.

In the fow cases of poisoning by this salt already recorded, as also in the numerous experiments upon animals, instituted by Sir Benjamin Brodie, Orfila, Gmelin, and Blake, phenomena closely resembling the foregoing have been obserred. but the order of sequence either has not always been clearly laid down, or would seem to differ, in some important respects, from that now stated; and one feature, interesting alike in a physiological as well as a toxicological point of view, is now noticed, I believe, for the first time-namely, the exemption of the nerves of sensation from the paralysing influence of the poison. This was so distinctly marked as to admit of no doubt.

With regard to the treatment employed in this case, the indications, of course, were to destroy the poison, as such, if possible, and to support the powers of life. To effect the first object, a solution of sulphate of magnesia was given, which, as everybody knows, forms, with solutions of the baryta salts, a compound - the sulphate-insoluble in nitric or hydrochloric acids, and, therefore, absolutely inert; but when it is considered that an hour and a half had elapsed from the receipt of the poison before this was administered; that there had been constant vomiting, caused either by the drug itself, or induced artificially, all the while; and that, moreover, the stomach had been repeatedly washed out with fluids, it will, I think, be admitted that there was but little ground for expecting much assistance from this agent, unless, indeed, it be assumed that its antidotal powers can operate through the circulation. But against this view, it appears to me, there are serious difficulties opposed. My chief hope, indeed, was, that by prolonging life the poison might be eliminated by the natural powers; and my efforts in this direction were for a time apparently suceessful; so much so, in fact, that for a while $I$ was quite sanguine of recovery, as was also my friend, Mr. Dyson, who saw the case with me in the afternoon. The advent, however, of the pulmonary lesion dispelled these hopes. In what did that untoward condition originate? Slowness of breathing and bronchial effusion have been remarked amongst the leading phenomena following division of the vagi nerves. May it, then, be sup. posed that the paralysis extended to these nerves? If so, then this may be regarded as the immediate cause of death in the present case, for the symptoms which succeeded-namely, the coma and convulsions, are but the normal results of impeded respiratory function. If this view of the facts be correct, it would seem to follow that barytes does not, in reality, possess narcotic properties.

It is necessary to say a word with respect to the quantity of the drug which was sufficient to cause death in this case. The girl's own statement, that she took less than a teaspoonful, was rather vague, and, indeed, was merely an answer to a leading question; but from a careful examination of all the facts bearing upon this point, I am satisfied that the amount 
taken did not much, if at all, exceed $\alpha d r a c h m$. It was taken mixed in water, but was not completely dissolved, and the stomach was empty at the time.

I regret that $\mathrm{I}$ am unable to complete this report by adding the post-mortem appearances. Perhaps, had I been more firm, the coroner would have granted an examination of the body; but the friends had private reasons for being opposed to it, which, under the circumstances, I felt bound to respect.

Manchester, 1859.

\section{a fitror}

OF THE PRACTICE OF

\section{MEDICINE AND SURGERY IN THE}

\section{HOSPITALS OF LONDON.}

Nulla est alia pro certo noscendi via, nisi quam plurimas et morborum et dissectionum historias, tam aliorum proprias, eollectas habere et inter se comparare.-Morgagnt. De Sed. et Cans. Morb., lib. 14. Proømium.

\section{LONDON HOSPITAL.}

STRANGULATED INGUINAI HERNIA; DESCENT OF INTESTINE IN A DISTINCT SAC BEHIND A LARGE HYDROCELE.

(Under the care of Mr. Adams and Mr. Nathanied Ward.)

A strong, healthy-looking man was admitted on Jan. 9th. There was a large tumour on the right side of the scrotum, extending along the inguinal canal as far as the internal ring. There was some amount of tenderness on pressure, and the patient complained of pain across the umbilical region, and a feeling of sickness. His bowels had acted on the morning of his admission. The man mentioned that he had had the swell$\mathrm{ng}$ as long as he could remember; he had never used a truss; and, with the exception of the tumour having ${ }_{4}^{7}$ somewhat increased in size a short time before his admission, there seemed to him nothing unusual about it. He was not aware that he had strained himself in any way. On a careful examination, the tumour was found to be pyriform in shape; its narrow extremity terminated abruptly at the situation of the inner ring. The body of the swelling appeared somewhat tilted to the right side, and, for a hydrocele, was unusually prominent and tense. On the removal of the fluid by tapping the structures situated behind and internal to it appeared thickened, and there was an amount of fulness which could not be naturally accounted for. There was, however, no defined tumour, nor could impulse on coughing be detected. The symptoms of intestinal obstruction not being well marked, $\mathrm{Mr}$. Ward, who was called to the case in the first instance, recommended that an exploratory operation should be deferred, and the case carefully watched.

On the morning of the following day, the abdominal pain had increased, and vomiting had supervened, the bowels being constipated; the residual swelling had increased; and on further careful examination by Mr. Adams, it was deemed expedient to operate. The man, however, would not consent to this until the afternoon, by which time the vomiting had become stercoraceous. The patient was placed under the influence of chloroform, the sac of the hydrocele was cut through, and a small hernial tumour was exposed, the cavity of the sac of which was opened, after the outer ring had been incised. The impediment to reduction was found at the neck of the sac. This being relieved, a small knuckle of highly-inflamed intestine was reduced.

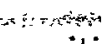

During the night, diarrhœea and vomiting set in; and the patient sank from collapse on the day following the operation, notwithstanding the free use of brandy and opium.

On a post-mortem examination, there was not found any evidence of peritonitis. The knuckle of intestine that had protruded was highly congested. The sac of the hernia was small, and situated internally to and behind the sac of the hydrocele, which latter extended upwards as far as the inner ring, in consequence of the non-obliteration of the funicular portion of the tunica vaginalis.
BLIQUE INGUINAL HERNIA IN A FEMALE; SAC ADHERENT TO GUT.

(Under the care of Mr. ADAMIs.)

The rarity of an inguinal hernia in a female renders the following case interesting:-

A spare woman, aged fifty-seven, married, was admitted on January $7 \mathrm{th}$, suffering from symptoms of strangulated inguinal hernia on the right side. The tumour was small, extending about an inch below the outer ring, and was tender to the touch. The patient appeared very weak, and her countenance had an expression as though she had been suffering much pain for a long period. Her tongue was parched and dry, and her pulse almost imperceptible. A fortnight prior to admission the bowel had descended, and she was unable to return it. The taxis was shortly after applied by a surgeon, and the greater portion of the bowel returned into the abdomen, a small tumour remaining behind in the groin. From this time she had suffered much pain about the abdomen, and almost constant retching or sickness. Her bowels had not acted. The taxis was not had recourse to after admission; but an operation, as a remote chance of saving life (considering the prostrated condition of the patient), was performed, wine having been previously administered. Mr. Adams made an incision over the external ring, which was incised. On the division of the transversalis fascia, a small quantity of blood-tinged fluid escaped, and the sac appeared to have been opened. On careful examination, however, of what appeared to be a highly congested knuckle of intestine, a thin membrane over the tumour could be pinched up between the finger and thumb. This was carefully divided with a scalpel, and turned out to be the attenuated peritoneal covering adherent by fibrin to the bowel, no fluid whatever intervening between the two. The sac was, therefore, carefully stripped away from the bowel by the aid of two forceps, and, on the division of its neck, the bowel was reduced. The finger was subsequently passed into the abdominal cavity, with the view of detecting and removing any further source of obstruction, if it existed.

The patient sank within an hour after the operation, and on a post-mortem examination the intestines were found generally healthy; there had been no peritonitis. The colon was flaccid and empty, and the bowel that had been strangulated, though much congested, was not gangrenous. The other organs of the body were healthy.

\section{ROYAL FREE HOSPITAL.}

\section{CASE OF SYPHILITIC GANGRENE OF THE MOUTH, WITH} IMPENDING SUFFOCATION.

OPERATION OF LARYNGOTOMY; RECOVERY.

(Under the care of Mr. DE MérId.

THE appearances presented by the patient in the following case for some days before impending suffocation set in, were such as to render the prognosis of the most serious kind; for the entire mouth seemed to be undergoing the sloughing process, the result of excessive ptyalism supervening some time after the cessation of the use of large doses of mercury. When we saw her in this state, it was almost an utter impossibility to get her to swallow fluids, which, together with the alreadyexisting debility, seemed slowly to be ushering in dissolution. The promptness in opening the larynx evinced by the housesurgeon when asphyxia had actually commenced, was followed by a favourable termination.

The necessity of opening the larynx and trachea, for the relief of actual syphilitic ulceration and its consequences, is occasionally forced upon the surgeon, as our "Mirror" has several times illustrated. But an instance like the present, in which the operation has been performed for mercurio-syphilitic gangrene of the mouth, is somewhat rare.

We are indebted to Mr. J. J. M'Gregor, house-surgeon to the hospital, for the notes of the case:-

E. P - aged nineteen, an unfortunate girl, was admitted into the female venereal ward of the hospital on the 29 th of October, $1 \supset 58$, under the eare of Mr. de Méric. She was suffering from secondary symptoms, both legs being covered with papular eruptions. Her constitution, too, was much debilitated by privation and excesses. On questioning her closely, it was ascertained that she first contracted syphilis at Portsmouth, about four months previous to her admission; that she then came up to London, and became an in-patient of Guy's Hos213 